\title{
Clinical characteristics, surgical strategies, and outcome of solid pseudopapillary tumor of the pancreas: retrospective analysis in a single center
}

\author{
Weigang Zhang, Junyi Qiu, Wuyang Bian, Ding Sun, Yang Shi, Lei Qin, Xiaofeng Xue \\ Department of General Surgery, The First Affiliated Hospital of Soochow University, Soochow, China
}

Videosurgery Miniinv 2022; 17 (1): 163-169

DOI: https://doi.org/10.5114/wiitm.2021.108804

\begin{abstract}
Introduction: Solid pseudopapillary tumor of the pancreas (SPTP) is a rarely diagnosed, low-malignancy pancreatic neoplasm, which mostly can be cured by surgery.

Aim: To investigate the surgical effect and prognosis of SPTP.

Material and methods: The data of 39 patients diagnosed with SPTP and treated with surgery between 2013 and 2020 were analyzed retrospectively. The data included the clinical characteristics, surgical management, pathological findings and therapeutic outcome.

Results: The mean age of the patients was $34.0 \pm 12.1$ years, and the female : male ratio was $32: 7$. Most of the patients were asymptomatic (48.7\%). The mean diameter of the tumors was $4.81 \pm 2.36 \mathrm{~cm}$. Operative procedures were conducted according to the location and size of the tumors. Laparoscopic surgery, especially laparoscopic distal pancreatectomy (LDP), provided a smaller incision, a shorter postoperative hospital stay and a shorter postoperative fasting time. There was no observed difference in the amount of blood loss or complication rate. The median follow-up was 24 months. One patient with 20\% expression of Ki-67 developed liver metastasis after surgery.

Conclusions: SPTP is a rare disease with low malignancy. Minimally invasive surgery, especially LDP, has been proven to be a feasible and safe treatment method for SPTP with early recovery. The prognosis of SPTP is favorable. Lifetime surveillance is necessary especially in patients with a high expression rate of Ki-67.
\end{abstract}

Key words: prognosis, solid pseudopapillary tumor of the pancreas, surgical management.

\section{Introduction}

Solid pseudopapillary tumor of the pancreas (SPTP) is a low-malignancy and rarely diagnosed tumor, which was first reported by Dr. Frantz in 1959 [1]. SPTP accounts for $1-3 \%$ of pancreatic tumors and $9 \%$ of pancreatic cyst tumors [2] and is dominant in young female patients (> $90 \%$ of cases) mostly between 30 and 40 years old [3]. In recent years, the prevalence of SPTP has increased due to the popularization of com- puted tomography (CT) examination. Most SPTPs are observed in the distal areas of the pancreas, while only one-third of the tumors are found in the head of the pancreas [4, 5]. In most cases, surgical resection was used to treat SPTPs. Although the malignancy rates are between $3.6 \%$ and $56 \%$ [6], the assessing standard for malignancy is flexible and is highly dependent on the preoperative image and intraoperative anatomy but not pathology. However, even with metastasis, the overall 5-year survival rate is approximately $97 \%$ [7].

\section{Address for correspondence}

Xiaofeng Xue, Department of General Surgery, The First Affiliated Hospital of Soochow University, Suzhou, China,

e-mail: xfxue@suda.edu.cn; Lei Qin, Department of General Surgery, The First Affiliated Hospital of Soochow University, Suzhou, China,

e-mail: qinlei@suda.edu.cn 
Table I. Demographics and clinical features of 39 patients with SPTP

\begin{tabular}{|c|c|}
\hline Clinical features & Value \\
\hline \multicolumn{2}{|l|}{ Sex, $n(\%):$} \\
\hline Male & $7(17.9)$ \\
\hline Female & $32(82.1)$ \\
\hline Age, mean \pm SD [years] & $34.0 \pm 12.1$ \\
\hline \multicolumn{2}{|l|}{ Symptoms, $n(\%):$} \\
\hline Asymptomatic & $19(48.7)$ \\
\hline Abdominal pain & $7(17.9)$ \\
\hline Abdominal discomfort & $9(23.1)$ \\
\hline Back pain & $3(7.7)$ \\
\hline Jaundice & $1(2.6)$ \\
\hline \multicolumn{2}{|l|}{ Tumor location, $n(\%)$ : } \\
\hline Head & $8(20.5)$ \\
\hline Neck & $12(30.8)$ \\
\hline Body and tail & $19(48.7)$ \\
\hline Tumor size, mean \pm SD $[\mathrm{cm}]$ & $4.81 \pm 2.36$ \\
\hline \multicolumn{2}{|l|}{ Type of surgery, $n$ (laparoscopic/open): } \\
\hline Enucleation & $2(1 / 1)$ \\
\hline Distal pancreatectomy + splenectomy & $14(8 / 6)$ \\
\hline Spleen-preserving distal pancreatectomy & $8(7 / 1)$ \\
\hline Middle pancreatectomy & $8(1 / 7)$ \\
\hline Pancreaticoduodenectomy & $7(3 / 4)$ \\
\hline RO resection rate, $\mathrm{n}(\%)$ & $39(100)$ \\
\hline Local/Vascular invasion, $n(\%)$ & $0(0)$ \\
\hline \multicolumn{2}{|l|}{ Postoperative complications, $n(\%)$; } \\
\hline Pancreatic fistula (grade B-C) & $7(17.9)$ \\
\hline Bleeding & $1(2.6)$ \\
\hline Wound infection & $0(0.0)$ \\
\hline Abdominal infection & $5(12.8)$ \\
\hline Delayed gastric emptying & $0(0.0)$ \\
\hline Intestinal fistula & $0(0.0)$ \\
\hline Chyle fistula & $2(5.1)$ \\
\hline Biliary fistula & $2(5.1)$ \\
\hline Mortality, $n(\%)$ & $0(0)$ \\
\hline Metastasis, $n(\%)$ & $1(2.6)$ \\
\hline Duration of operation, mean \pm SD [min] & $254.1 \pm 107.3$ \\
\hline Postoperative hospital stay, mean \pm SD [days] & $12.2 \pm 8.3$ \\
\hline
\end{tabular}

Aim

With the development of laparoscopic techniques, the minimally invasive approach for treating SPTP is accepted by the young population, benefiting from its smaller incision compared with open surgery while maintaining the same level of safety $[8,9]$. However, few studies focus on this specific tumor. We summarized our limited knowledge of SPTP treatment and the outcome of the patients, especially on the evolving operative management from open to laparoscopic surgery.

\section{Material and methods}

In this study, 39 patients with SPTP between January 2013 and December 2020 were analyzed. SPTPs were pathologically confirmed for all the patients based on histological and immunohistochemical examinations after the surgery. The demographics, perioperative, intraoperative, and pathological variables of the SPTP patients with surgery treatment were described.

Follow-up included clinical manifestations, laboratory examinations, and abdominal enhanced CT scan. The patients were followed up in an outpatient setting by phone interview every year.

\section{Statistical analysis}

SPSS (IBM, version 22.0) was used to conduct the statistical analysis. The continuous data were analyzed with Student's $t$-test and the categorical variable data were analyzed with Fisher's exact test. A $p$-value smaller than $<0.05$ was considered significant.

\section{Results}

\section{General characteristics of resected SPTPs}

During the last 8 years, a total of 39 cases were identified and surgically resected with SPTP in our center. The general characteristics of SPTP are listed in Table I. There were 32 (82.1\%) female patients and $7(17.9 \%)$ male patients, and the mean age was $34.0 \pm 12.1$ years, ranging from 13 to 62 years. The prevalence of SPTP was dominant in young females, as the number of patients under 40 years was $29(74.4 \%)$ and $89.7 \%$ were female (26/29). The mean tumor diameter was $4.81 \pm 2.36 \mathrm{~cm}$, ranging from 1.2 to $13 \mathrm{~cm}$.

The SPTPs were incidentally found without specific symptoms in nearly half of the patients $(n=19$, 
48.7\%), while the rest of the patients presented with abdominal pain ( $n=7,17.9 \%)$, abdominal discomfort $(n=9,23.1 \%)$, back pain $(n=3,7.7 \%)$, or slight jaundice ( $n=1,2.6 \%$ ). It is possible for the tumor to appear in any area of the pancreas. Among the 39 cases, the majority of the tumors (19 cases) were located in the body and tail of the pancreas (48.7\%), 12 were located in the neck of the pancreas (30.8\%) and 8 in the head of the pancreas (20.5\%). A preoperative CT scan or magnetic resonance imaging (MRI) was performed on all the patients to confirm the presence of a pancreatic mass. Of the 32 tumors examined in our hospital, 25 were solid-cystic, 3 were completely cystic and 4 were completely solid. Intracystic hemorrhage was observed in 3 cases and calcification was observed in 6 cases (Photo 1 shows the different CT manifestations of SPTP). The diagnosis of SPTP was confirmed radiologically in 23 cases. Endoscopic ultrasound-guided fine-needle aspiration biopsy (EUS-FNA) was conducted in 3 patients; among them, two were suspected to be neuroendocrine tumors and one was diagnosed as SPTP.

\section{Postoperative outcome}

The surgery approach was selected mainly related to the location and size of the tumor. With the development of surgical techniques, the application of laparoscopic surgery has been increasing. Distal pancreatectomy was conducted in twenty-two patients (seven open with one spleen sparing, fifteen laparoscopic with seven spleen sparing), pancreaticoduodenectomy was conducted in 7 patients (four open, three laparoscopic), middle pancreatectomy was conducted in 8 patients (seven open, one laparoscopic), and tumor enucleation was conducted in 2 patients (one open, one laparoscopic). The mean operation time for both open and laparoscopic surgery was $254.1 \pm 107.3 \mathrm{~min}$. Four patients from 2013 to 2015 were treated by open surgery due to the lack of laparoscopic pancreatic surgical programs in our institute. Since 2015, 20 out of 35 (57.1\%) patients have been successfully treated with laparoscopic operations. Notably, due to a clear view after the enlargement in the distal pancreatectomy (DP) group, it was easier to preserve the spleen in the laparoscopic approach. One patient underwent pancreaticoduodenectomy (PD), in which the superior mesenteric vein (SMV) was resected and the artificial vessel was reconstructed. Another patient underwent enucleation with partial duodenectomy owing to a suspected local invasion of the tumor. All the patients got the RO resection margin both in the open and laparoscopic surgery. The most common postoperative complication was Grade B-C pancreatic fistula (17.9\%). Other complications included abdominal infection (12.8\%), biliary fistula (5.1\%), chyle fistula (5.1\%) and bleeding (2.6\%). One patient who developed intra-abdominal bleeding underwent further interventional arterial embolism. The total mortality rate of all the 39 patients for surgery was $0 \%$.

Minimally invasive procedures were successfully conducted in $51.3 \%$ (20/39) of the patients. We compared the duration of the surgery, blood loss, length of the incision, postoperative fasting time, postoperative hospital stay and complication rate between the patients who received the minimally

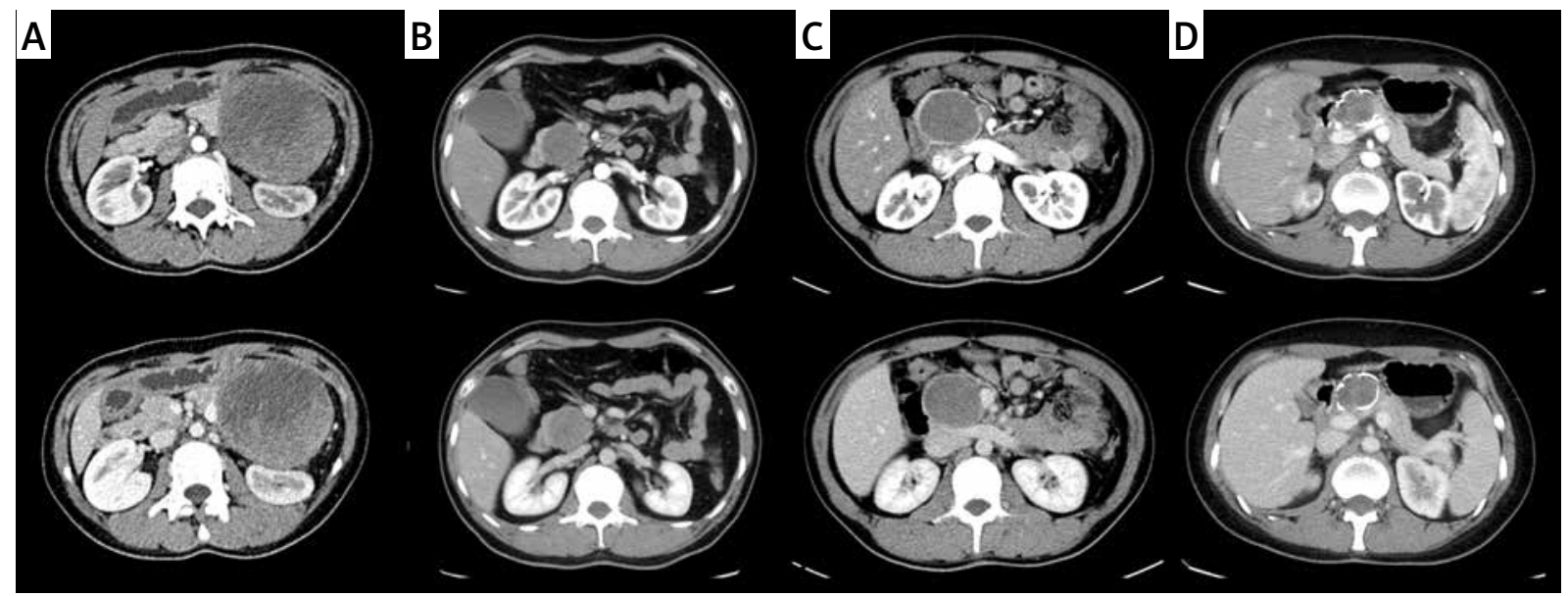

Photo 1. Different CT manifestations of SPTP: solid-cystic (A), complete solid (B), complete cystic (C), calcification (D) 
invasive surgery and those who did not (Table II). No significant difference was observed in regard to the duration of surgery $((263.2 \pm 78.7)$ min vs. $(244.6$ $\pm 130.1) \mathrm{min}, p>0.05)$, blood loss $((175.0 \pm 103.1) \mathrm{ml}$ vs. $(236.3 \pm 231.5) \mathrm{ml}, p>0.05)$, or complication rate (Clavien-Dindo II-IV) (25\% vs. $31.6 \%, p>0.05)$ between the laparoscopy and open group. Significant differences were detected in postoperative fasting time $((1.8 \pm 1.1)$ days vs. $(3.8 \pm 1.8)$ days, $p<0.05)$, postoperative hospital stay $((9.6 \pm 3.4)$ days vs. (14.9 $\pm 10.7)$ days, $p<0.05)$ and incision length $((5.3 \pm 1.8)$ $\mathrm{cm}$ vs. $(18.2 \pm 4.3) \mathrm{cm}, p<0.05)$. Additionally, we further divided the patients into four subgroups: enucleation, distal pancreatectomy, middle pancreatectomy, and pancreaticoduodenectomy (Table II). We then compared the same indexes between the minimally invasive surgery group and the non-minimally invasive surgery group separately. Comparing laparoscopic surgery with open surgery, there was nearly no difference in either the blood loss or the complication rate between the two treatment types in all subgroups $(p>0.05)$. In the distal pancreatectomy group, although laparoscopic surgery involved a longer operation time, it was associated with a shorter postoperative fasting time $((1.3 \pm 0.8)$ days vs. (3.1 $\pm 1.8)$ days, $p<0.05)$ and a shorter postoperative hospital stay $((8.4 \pm 2.3)$ days vs. $(10.6 \pm 1.8)$ days, $p<0.05)$ compared to the open surgery. The incision length was smaller in all laparoscopic subgroups $(p<0.05)$. In addition, there was no difference in the complication rate in every subgroup separately.

\section{Pathology assessment and immunohistochemistry}

Pathology assessment mainly included the location, size, and capsule completeness of the tumor, local or vascular invasion, lymph node metastasis and immunohistochemistry (IHC) expression. All patients reached the negative surgical margins and none of them had lymph node metastasis or distal metastasis. The results of IHC studies were summarized in Table III. Ki-67, $\beta$-catenin, vimentin and CD-10 were all $100 \%$ positively stained, while $\alpha$-ACT

Table II. Operative procedure and postoperative outcome for SPTP

\begin{tabular}{|c|c|c|c|c|c|c|c|c|c|}
\hline \multirow[t]{2}{*}{ Variable } & \multicolumn{3}{|c|}{ Duration of surgery [min] } & \multicolumn{3}{|c|}{ Blood loss [ml] } & \multicolumn{3}{|c|}{ Length of incision [cm] } \\
\hline & $\begin{array}{l}\text { Laparo- } \\
\text { scopic }\end{array}$ & Open & $P$-value & $\begin{array}{l}\text { Laparo- } \\
\text { scopic }\end{array}$ & Open & $P$-value & $\begin{array}{l}\text { Laparo- } \\
\text { scopic }\end{array}$ & Open & $P$-value \\
\hline Enucleation & 144 & 113 & - & 200 & 50 & - & 5 & 12 & - \\
\hline $\begin{array}{l}\text { Distal pan- } \\
\text { createctomy }\end{array}$ & $241.5 \pm 56.3$ & $176.4 \pm 57.2$ & $<0.05^{\star}$ & $170.0 \pm 116.6$ & $200.0 \pm 88.6$ & $>0.05$ & $5.1 \pm 1.6$ & $18.4 \pm 2.2$ & $<0.05^{\star}$ \\
\hline $\begin{array}{l}\text { Middle pan- } \\
\text { createctomy }\end{array}$ & 350 & $272.7 \pm 98.2$ & - & 250 & $238.6 \pm 208.6$ & - & 4 & $17.0 \pm 5.5$ & - \\
\hline $\begin{array}{l}\text { Pancreati- } \\
\text { co-duo- } \\
\text { denectomy }\end{array}$ & $382.3 \pm 40.7$ & $347.5 \pm 182.7$ & $>0.05$ & $166.7 \pm 23.6$ & $342.5 \pm 323.1$ & $>0.05$ & $6.3 \pm 2.6$ & $21.2 \pm 2.2$ & $<0.05^{*}$ \\
\hline Total & $263.2 \pm 78.7$ & $244.6 \pm 130.1$ & $>0.05$ & $175.0 \pm 103.1$ & $236.3 \pm 213.5$ & $>0.05$ & $5.3 \pm 1.8$ & $18.2 \pm 4.3$ & $<0.05^{\star}$ \\
\hline \multirow[t]{2}{*}{ Variable } & \multicolumn{3}{|c|}{ Postoperative fasting time [day] } & \multicolumn{3}{|c|}{ Postoperative hospital stay [day] } & \multicolumn{3}{|c|}{ Complication rate (\%) } \\
\hline & $\begin{array}{l}\text { Laparo- } \\
\text { scopic }\end{array}$ & Open & $P$-value & $\begin{array}{l}\text { Laparo- } \\
\text { scopic }\end{array}$ & Open & $P$-value & $\begin{array}{l}\text { Laparo- } \\
\text { scopic }\end{array}$ & Open & $P$-value \\
\hline Enucleation & 2 & 8 & - & 6 & 12 & - & $0(0 / 1)$ & $100(1 / 1)$ & - \\
\hline $\begin{array}{l}\text { Distal pan- } \\
\text { createctomy }\end{array}$ & $1.3 \pm 0.8$ & $3.1 \pm 1.8$ & $<0.05^{\star}$ & $8.4 \pm 2.3$ & $10.6 \pm 1.8$ & $<0.05^{\star}$ & $20(3 / 15)$ & $14.3(1 / 7)$ & $>0.05$ \\
\hline $\begin{array}{l}\text { Middle pan- } \\
\text { createctomy }\end{array}$ & 2 & $4.1 \pm 1.0$ & - & 13 & $12.0 \pm 4.1$ & - & $0.0(0 / 1)$ & $28.6(2 / 7)$ & - \\
\hline $\begin{array}{l}\text { Pancreati- } \\
\text { co-duo- } \\
\text { denectomy }\end{array}$ & $3.7 \pm 0.9$ & $3.3 \pm 1.6$ & $>0.05$ & $15.3 \pm 2.1$ & $28.3 \pm 16.7$ & $>0.05$ & $66.7(2 / 3)$ & $50(2 / 4)$ & $>0.05$ \\
\hline Total & $1.8 \pm 1.1$ & $3.8 \pm 1.8$ & $<0.05^{\star}$ & $9.6 \pm 3.4$ & $14.9 \pm 10.7$ & $<0.05^{\star}$ & $25(5 / 20)$ & $31.6(6 / 19)$ & $>0.05$ \\
\hline
\end{tabular}


Table III. Results of immunohistochemical profile of SPTPs in 39 patients

\begin{tabular}{|c|c|c|c|c|c|}
\hline \multirow[t]{2}{*}{ Antigen } & \multirow[t]{2}{*}{ Total number } & \multirow[t]{2}{*}{ Negative } & \multicolumn{2}{|c|}{ Positive } & \multirow{2}{*}{$\begin{array}{c}\text { Positive rate } \\
\text { (\%) }\end{array}$} \\
\hline & & & Weak $(-/+)$ & Positive (+) & \\
\hline Synaptophysin & 38 & 8 & 16 & 14 & 78.95 \\
\hline Chromogranin A & 34 & 34 & 0 & 0 & 0 \\
\hline Vimentin & 33 & 0 & 6 & 27 & 100 \\
\hline Cytokeratin & 31 & 13 & 13 & 5 & 58.06 \\
\hline Ki-67 & 38 & 0 & 0 & 38 & 100.0 \\
\hline$\beta$-catenin & 31 & 0 & 1 & 30 & 100.0 \\
\hline Progesterone receptor & 27 & 7 & 8 & 12 & 74.07 \\
\hline CD-10 & 27 & 0 & 7 & 20 & 100.0 \\
\hline$\alpha-A C T$ & 18 & 1 & 0 & 17 & 94.44 \\
\hline CD-56 & 24 & 1 & 4 & 19 & 95.83 \\
\hline Neuron-specific enolase & 9 & 2 & 3 & 4 & 77.78 \\
\hline CK7 & 25 & 24 & 1 & 0 & 4 \\
\hline S100 & 11 & 8 & 3 & 0 & 27.27 \\
\hline
\end{tabular}

and CD-56 were nearly $100 \%$ positive in the detected samples. Chromogranin A (CgA) was 100\% negative in the detected samples. Thirty-eight patients had a Ki-67 index ranging from $1 \%$ to $20 \%$; among them six were over $4 \%$ and one was as high as $20 \%$. The remaining immunohistochemical profiles were differently expressed.

\section{Follow-up}

The last follow-up was conducted in March 2021. The median follow-up time was 24 months (range: 3-84 months). All patients were disease-free except one who developed single liver metastasis at 19 months after surgery and then underwent liver tumor resection in another hospital. No new recurrence or metastasis was detected during the 6-month follow-up after the resection of the hepatic metastatic lesion. A whole-life follow-up is indispensable after resections of SPTPs due to potential malignancy of the relapse and metastatic capacity.

\section{Discussion}

As a rarely diagnosed tumor, SPTP is considered low malignancy and occurs mostly in young women. The reported female/male ratio of the patients was $10: 1[10,11]$ while in our study the ratio was $32: 7$. Female hormones seem to affect pathogenesis, but no differences in sex hormone-receptor protein expression have been found so far [12].
SPTP usually lacks specific manifestations and nearly $50 \%$ of the patients in our study presented asymptomatically. The incidence of SPTP has increased due to more application of the CT scan. SPTP is commonly featured in calcification, cystic change, and internal hemorrhage owing to a lack of vessels [13]. CT imaging of SPTP with an HU value over 62.6 of the solid component on the delayed contrast phase and progressive enhancement appears more malignant [14]. In addition, the FDG uptake of SPT on PET-CT was associated with tumor cellularity, proliferation index, and histological malignancy [15].

Immunohistochemistry (IHC), a diagnostic gold standard for SPTP, helps to differentiate SPTP from pancreatic neuroendocrine tumors (pNETs) and other cystic tumors [16]. $\beta$-catenin is considered the most important feature of SPTP [17-19], which is $100 \%$ positively stained as well as Ki-67, vimentin and CD-10 in our study. It is reported that the Ki-67 index over $4 \%$ is associated with relapse and metastasis during the follow-up [3, 20, 21]. In our study, the patients with liver metastasis after surgery had a $20 \% \mathrm{Ki}-67$ rate.

The curative treatment for SPTP is surgical resection. We performed operations once the abdominal imaging suggests a possibility of SPTP, or when the pathology of EUS-guided biopsy suggests cellular atypia. The selection of surgical approach mainly depends on the location and size of the tumor. With the technological advances in recent years, the lap- 
aroscopic operation is rapidly gaining popularity in pancreatic tumor resection. Even for highly technically demanding pancreaticoduodenectomy, the procedure could be completed under laparoscopy after mastering the technical details as well as tips and tricks [22]. The laparoscopic approach benefits from the better view of the vessels attributable to the magnified images and special view from the inferior posterior side of pancreas. Patients treated with the laparoscopic approach seem to be less debilitated with less wound infection, a shorter hospital stay, an earlier recovery and an improved cosmetic outcome [10]. Minimally invasive surgery is an ideal treatment for SPTP, because SPTP is typically rarely invasive to the surrounding tissues while highly associated with the body and tail of the pancreas.

Laparoscopic distal pancreatectomy has become the gold standard approach to deal with distal pancreas lesions [23]. As low-grade malignant tumor, SPTP is a potential candidate for splenic preservation during distal pancreatectomy, which has demonstrated feasibility and safety compared with traditional distal pancreatectomy, including a similar rate of postoperative complications, less epigastric varices formation and reduced risk of postsplenectomy sepsis [24, 25]. In our report, about half of the patients had a laparoscopic resection. In our study, the minimally invasive approach seems to have a superior therapy outcome to the open operation in terms of the incision length, postoperative fasting time and length of hospital stay, while the blood loss and complication rate were similar between the two approaches. These results suggested that compared with traditional open surgery, minimally invasive surgery may obtain similar safety and be superior with a smaller incision and shorter recovery time.

Based on the published data, the overall 5-year survival rate and ten-year survival rate for SPTP are $88-97 \%$ and $89.6-96 \%$, respectively $[2,7,12,26$, 27]. The recurrence rate for SPTP ranges from $1.9 \%$ to $15 \%$ as reported $[2,12,27,28]$. Some reports suggested that features such as pancreatic duct dilation, vessel infiltration, and capsule damage may be associated with recurrence $[29,30]$. Metastases can be present at diagnosis or years after resection. Metastases mostly occur in the liver and peritoneum [31]. Most centers offer further surgery if the metastatic disease is resectable [11], and these patients can survive long term after the resection [32, 33].
According to the previous studies, most recurrences occurred more than 5 years after resection; thus, an over 5-year follow-up is indispensable after resections of SPTPS $[4,34]$.

\section{Conclusions}

SPTP is a rare disease with low malignancy. Minimally invasive surgery is proven to be a feasible and safe approach to treat this disease because of the smaller incision, shorter postoperative fasting time and shorter postoperative hospital stay. The 5-year and ten-year survival rate is quite good after surgery. Long-time surveillance is essential after resections. Further research investigating the molecular mechanism and clinical characteristics of SPTP is needed to assist the diagnosis, treatment, and prediction of SPTP.

\section{Acknowledgments}

Weigang Zhang and Junyi Qiu contributed equally to this work.

\section{Conflict of interest}

The authors declare no conflict of interest.

\section{References}

1. Frantz, V. Tumor of the pancreas. Atlas of tumor pathology. $1^{\text {st }}$ series. DC: US Armed Forces Institute of Pathology, Washington 1959; 32-3.

2. Papavramidis T, Papavramidis S. Solid pseudopapillary tumors of the pancreas: review of 718 patients reported in English literature. J Am Coll Surg 2005; 200: 965-72.

3. Yu PF, Hu ZH, Wang XB, et al. Solid pseudopapillary tumor of the pancreas: a review of 553 cases in Chinese literature. World J Gastroenterol 2010; 16: 1209-14.

4. Butte JM, Brennan MF, Gonen M, et al. Solid pseudopapillary tumors of the pancreas. Clinical features, surgical outcomes, and long-term survival in 45 consecutive patients from a single center. J Gastrointest Surg 2011; 15: 350-7.

5. Reddy S, Cameron JL, Scudiere J, et al. Surgical management of solid-pseudopapillary neoplasms of the pancreas (Franz or Hamoudi tumors): a large single-institutional series. J Am Coll Surg 2009; 208: 950-7.

6. Morikawa T, Onogawa T, Maeda S, et al. Solid pseudopapillary neoplasms of the pancreas: an 18-year experience at a single Japanese Institution. Surg Today 2013; 43: 26-32.

7. Tang LH, Aydin H, Brennan MF, et al. Clinically aggressive solid pseudopapillary tumors of the pancreas: a report of two cases with components of undifferentiated carcinoma and a comparative clinicopathologic analysis of 34 conventional cases. Am J Surg Pathol 2005; 29: 512-9. 
8. Stewart CL, Meguid C, Chapman B, et al. Evolving trends towards minimally invasive surgery for solid-pseudopapillary neoplasms. Ann Surg Oncol 2016; 23: 4165-8.

9. Senthilnathan P, Dhaker KC, Kaje V, et al. Laparoscopic management of solid pseudo papillary neoplasm of pancreas in tertiary care center from south India. Pancreatology 2017; 17: 927-30.

10. Cuccurullo D, Carbone G, lovino MG, et al. Solid pancreatic pseudopapillary tumor managed laparoscopically: a case report and review of the literature. Int I Surg Case Rep 2018; 45: 4-8.

11. Lubezky N, Papoulas M, Lessing Y, et al. Solid pseudopapillary neoplasm of the pancreas: Management and long-term outcome. Eur J Surg Oncol 2017; 43: 1056-60.

12. Sunkara S, Williams TR, Myers DT, et al. Solid pseudopapillary tumours of the pancreas: spectrum of imaging findings with histopathological correlation. Br J Radiol 2012; 85: e1140-4.

13. Kim SS, Choi GC, Jou SS. Pancreas ductal adenocarcinoma and its mimics: review of cross-sectional imaging findings for differential diagnosis. J Belgian Soc Radiol 2018; 102: 71.

14. Rastogi A, Assing M, Taggart M, et al. Does computed tomography have the ability to differentiate aggressive from nonaggressive solid pseudopapillary neoplasm? J Comp Assist Tomography 2018; 42: 405-11.

15. Ambros $V$. The functions of animal microRNAs. Nature 2004; 431: 350-5

16. Shaikh S, Arya S, Ramadwar M, et al. Three cases of unusual solid pseudopapillary tumors. Can radiology and histology aid decision-making? JOP 2008; 9: 150-9.

17. Hackeng WM, Hruban RH, Offerhaus GJ, et al. Surgical and molecular pathology of pancreatic neoplasms. Diagn Pathol 2016; 11: 47.

18. Kim MJ, Jang SJ, Yu E. Loss of E-cadherin and cytoplasmic-nuclear expression of beta-catenin are the most useful immunoprofiles in the diagnosis of solid-pseudopapillary neoplasm of the pancreas. Human Pathol 2008; 39: 251-8.

19. Tipton SG, Smyrk TC, Sarr MG, et al. Malignant potential of solid pseudopapillary neoplasm of the pancreas. Br I Surg 2006; 93: 733-7.

20. Guo N, Zhou QB, Chen RF, et al. Diagnosis and surgical treatment of solid pseudopapillary neoplasm of the pancreas: analysis of 24 cases. Can J Surg 2011; 54: 368-74.

21. Yang F, Yu X, Bao Y, et al. Prognostic value of Ki-67 in solid pseudopapillary tumor of the pancreas: Huashan experience and systematic review of the literature. Surgery 2016; 159: 1023-31.

22. Triantafyllidis I, Gayet B, Fuks D. Tips and tricks for a safe laparoscopic pancreatoduodenectomy. Videosurgery Miniinv 2020; 15: 383-90.

23. Mehrabi A, Hafezi M, Arvin J, et al. A systematic review and meta-analysis of laparoscopic versus open distal pancreatectomy for benign and malignant lesions of the pancreas: it's time to randomize. Surgery 2015; 157: 45-55.

24. Shoup M, Brennan MF, McWhite K, et al. The value of splenic preservation with distal pancreatectomy. Arch Surg 2002; 137: 164-8.

25. Chen S, Zhan Q, Chen JZ, et al. Robotic approach improves spleen-preserving rate and shortens postoperative hospital stay of laparoscopic distal pancreatectomy: a matched cohort study. Surg Endosc 2015; 29: 3507-18.
26. El Nakeeb A, Abdel Wahab M, Elkashef WF, et al. Solid pseudopapillary tumour of the pancreas: Incidence, prognosis and outcome of surgery (single center experience). Int I Surg 2013; 11: 447-57.

27. Song H, Dong M, Zhou J, et al. Solid pseudopapillary neoplasm of the pancreas: clinicopathologic feature, risk factors of malignancy, and survival analysis of 53 cases from a single center. BioMed Res Int 2017; 2017: 5465261.

28. Lubezky N, Papoulas M, Lessing Y, et al. Solid pseudopapillary neoplasm of the pancreas: management and long-term outcome. Eur J Surg Oncol 2017; 43: 1056-60.

29. Kang CM, Choi SH, Kim SC, et al. Predicting recurrence of pancreatic solid pseudopapillary tumors after surgical resection: a multicenter analysis in Korea. Ann Surg 2014; 260: 348-55.

30. Kim CW, Han DJ, Kim J, et al. Solid pseudopapillary tumor of the pancreas: can malignancy be predicted? Surgery 2011; 149: 625-34.

31. Klimstra DS, Wenig BM, Heffess CS. Solid-pseudopapillary tumor of the pancreas: a typically cystic carcinoma of low malignant potential. Semin Diagn Pathol 2000; 17: 66-80.

32. Lam KY, Lo CY, Fan ST. Pancreatic solid-cystic-papillary tumor: clinicopathologic features in eight patients from Hong Kong and review of the literature. World I Surg 1999; 23: 1045-50.

33. Nishihara K, Nagoshi M, Tsuneyoshi M, et al. Papillary cystic tumors of the pancreas. Assessment of their malignant potential. Cancer 1993; 71: 82-92.

34. Gao H, Gao Y, Yin L, et al. Risk factors of the recurrences of pancreatic solid pseudopapillary tumors: a systematic review and meta-analysis. J Cancer 2018; 9: 1905-14.

Received: 26.06.2021, accepted: 8.08.2021. 